\title{
Changing Urban Traits - A study on Bengaluru Urban Agglomeration, India
}

\author{
Priyadarshini Sen ${ }^{1}$ \\ ${ }^{1}$ Department of Geography, Dum Dum Motijheel College, Kolkata, India \\ Correspondance: Priyadarshini Sen, Department of Geography, Dum Dum Motijheel College, 419, Dum Dum \\ Road, Kolkata 700074, India. E-mail: priyadarshinigeo@gmail.com
}

Received: October 8, 2012 Accepted: November 4, 2012 Online Published: December 31, 2012

doi:10.5539/ass.v9n1p122 URL: http://dx.doi.org/10.5539/ass.v9n1p122

\begin{abstract}
Bengaluru once a tiny village in the $12^{\text {th }}$ Century grew through times to become one of the fastest growing cities in the world in the $21^{\text {st }}$ Century. A city of the past, present and future is unlike any other cities in India, yet is a very much Indian city; it has a history of 450 years. The following essay presents the history about Bengaluru, its growth and changing land use and development from a traditional royal kingdom to the country's leading software destination. Ideologically the concept of conurbation introduced by Patric Geddes (1915) signified a growth process of built - up structure in the rural enclaves in between a chain of towns generally linked to a primate city. Further, T.W. Freeman introduced the term agglomeration given by a central city with satellite towns. For Bengaluru, the process of sprawl of a primate city is well linked to the essential expansion of itself encompassing the other towns and growth foci. Objective of this paper is to highlight the city of Bengaluru in the context of its changing land use and growing influence on the rest of the urban centres of Karnataka state. Besides suburban growth has been dominant for the developing countries since late $20^{\text {th }}$ Century which began with the movement of the wealthy and gradually spread down through all classes in the society with improving transport networks.
\end{abstract}

Keywords: garden city, land use, spiller cities, urbanism, urban primacy

\section{Introduction}

Cities usually pose a far reaching impact on the global environment. But urban areas in less economically developed countries are characterised by inequalities in the quality of urban life. The growth of cities inevitably leads to a growth in the demand for basic services, facilities and opportunities. The demand for housing, water, sanitation, employment and public services such as education is nearly always in excess of the city's capacity to provide them. In this regard, change in land use characteristics is perhaps the most visible impact as far as the city's peripheral expansion is concerned. Bengaluru has grown, both in size and in population, phenomenally during the last decade. There is an urgent need to reassess the land policies at the state level to address the issues of inclusive and equitable growth opportunities. Existing practices and policies regarding urban land use, zoning and development cannot manage the situation efficiently and major efforts are required to improve land market efficiency. There are indeed three closely related aspects of defining towns; that can be distinguished for analytical purposes. They are the physical growth of individual cities in a 'brick and mortar' sense, followed by the emergence of functional specialization of cities and distinctive social and economic changes that characterise a city. Most people now live in democratic states, and decentralization has increased apace, noticeably in India. The country belonging to Medium Human Development Index position shares its population of about 30 percent as urban in 2010 (Human Development Report, 2010) perhaps faces the major challenges answering the notions of regional disparities amongst its various urban centres.

\section{Area of Study}

The overall purpose of this study is to understand the spatial and socioeconomic development impacts of the land use planning and development regulations in Bengaluru and to examine how best the urban land markets responded to the planning initiatives and what are the broader implications of these relationships and how best to bring out the functional and management synergies of these two important structures of urban growth. The city happens to be one of the fastest growing of its kind in the south Asia with perhaps every element of urbanism. One of the visible changes here is its changing land use that has accelerated its areal expansion. There has been a 
variety of attempts by the urban geographers create urban models for certain cities in making. So are they for the city in discussion too. Planning for land use is indeed a challenge for a city like Bengaluru where the rich and poor are spatially segregated into separate neighbourhoods. In this context growing slums are its inevitable cause indicating inequality and haphazard expansion. Bengaluru is relatively a circular city unlike to that of Mumbai and Kolkata, showing a linear pattern of urban expansion. In the last five years the Garden City has added over ten kilometres in all directions. As per the Comprehensive Development Plan, the existing urbanised area in the city covers an area of 512 square kilometres with 300 square kilometres of proposed area to be further urbanised. The expansion of the city to its northern part is majorly due to the emergence of newly formed International Airport. Eastern part of the city has grown beyond Whitefield and southern part has captured the state boundaries if not beyond. Managing land use and taming the haphazard growth of the city is perhaps one of the most challenging tasks for the planners and urban geographers as the city in question should be a focus of development and at the same time should not cause hindrance towards the growth of other centres as well.

\section{Urbanscape of Bengaluru}

There has been scope for understanding the urban behaviour of any region given its historical evolution through population concentration and influence of the same in getting together the major infrastructural facilities promoting further growth. Looking at the city's growing population, it is evident that it recorded an ever growing population from the decades from 1901 up till 2011 which has projected to rise even more for the coming decades.(Figure 1).The decadal population growth had experienced two 'peaks', one in the year 1950-51 due to population migration to Bengaluru after independence and another during 1980 ,after the software industry boom in India where it emerged to be the silicon valley of the country and the business destination for many off-shore countries.

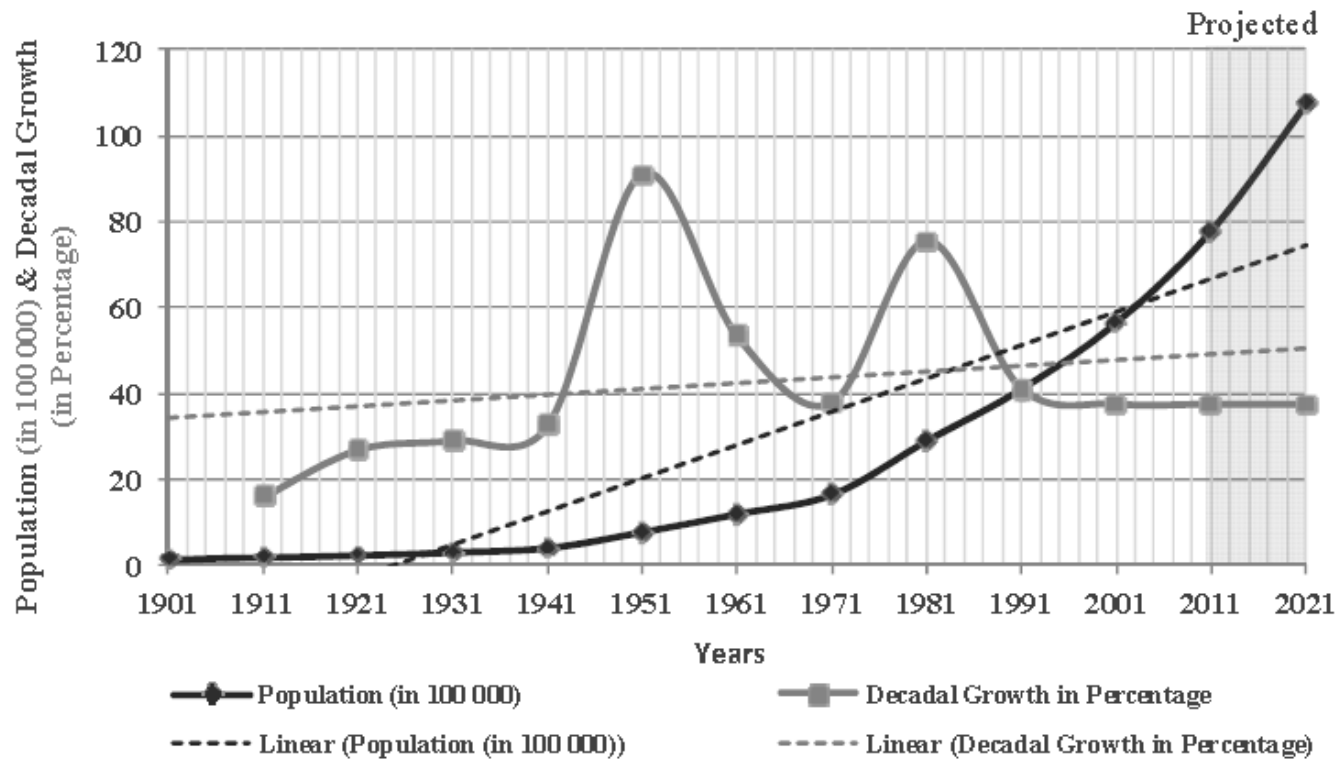

Figure 1. Increase of population and its decadal growth (actual \& projected) Bengaluru (1901-2021)

Source: Census of India, $2001 \&$ (provisional) 2011

\subsection{Evolution of the City}

The city evolved historically from a stage where it was statued as a hamlet into matured developed urban agglomeration, passing through the stages of boundary defining and redefining. Coins of Roman Emperors like Augustus, Tyberius and Cladius were found at the eastern part of the city indicating its transoceanic contacts that dated back to 27 BC (Bangalore through the Ages, Census of India, 2001). The name Bengaluru occurred for the first time on a ninth century stone inscription at Begur when it was merely a village under Ganga Kingdom later came under the Cholas. Land use records date back to the years of late $19^{\text {th }}$ century when whole of Indian subcontinent was under British regime. Still the year 1862 was significant where two municipal boards were formed one for the city and the other for the cantonment area .In the year 1862 the city of today maintained its fort centric behaviour and railway lines touching both Mysore and the city palace of Bengaluru (Figure 2a). Bengaluru gained a geographical entity during 1891 typically fort-centric at its north; the railway line and road line touching its location well connecting the area around (Figure 2b).An almost thirty years span has visibly impacted the city mostly in respect to its areal expansion. Besides during the year 1910-1911 the land use reveals 
a south eastward expansion (Figure 2c). A denser transport network over the years is indicative of demanding traffic flow hence more population concentration. A radially growing settlement is indicative of the growing city (Figure 2d).

After independence, in the year 1949, the Bangalore Municipal Corporation formed by merging the city, civil and military bases. It became the capital of unified Greater Mysore; later Bengaluru area was bifurcated into two districts namely Bengaluru urban and Bengaluru rural. Such bifurcation was more apparent than real as growing Bengaluru would take up its rural counterpart.

Figure 2a. Bengaluru -1862

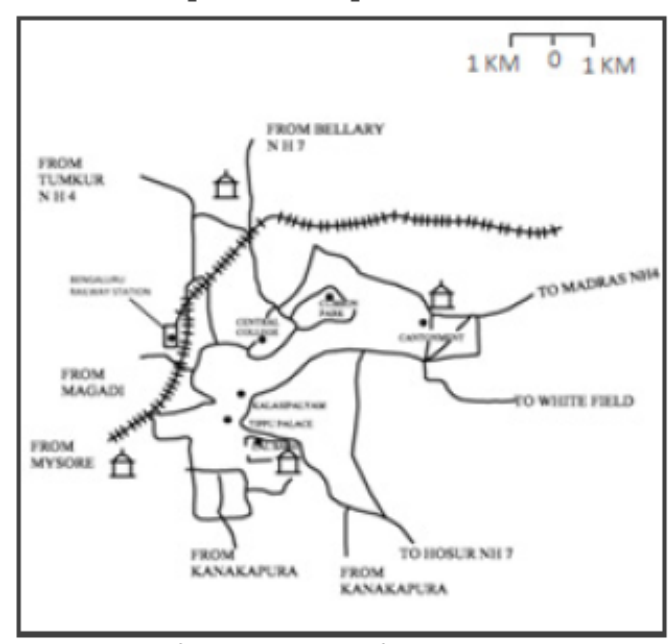

Figure 2c. Bengaluru - 1911

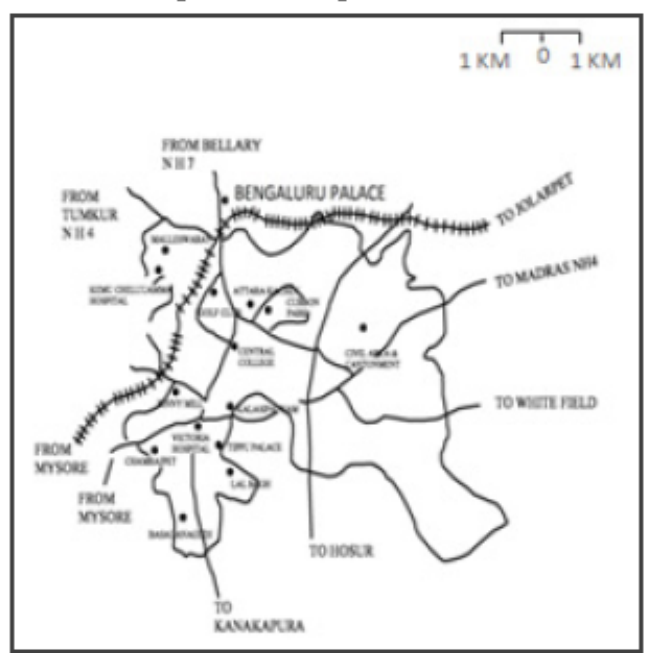

Figure 2b. Bengaluru - 1891

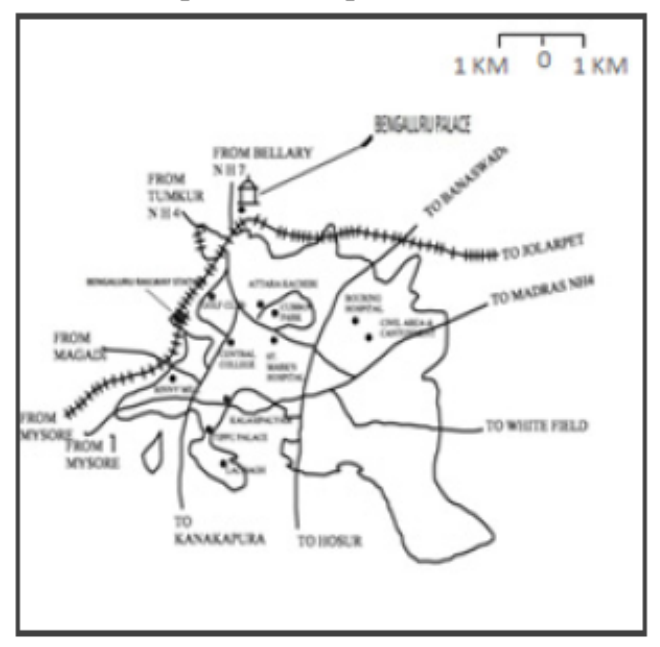

Figure 2d. Bengaluru - 2001

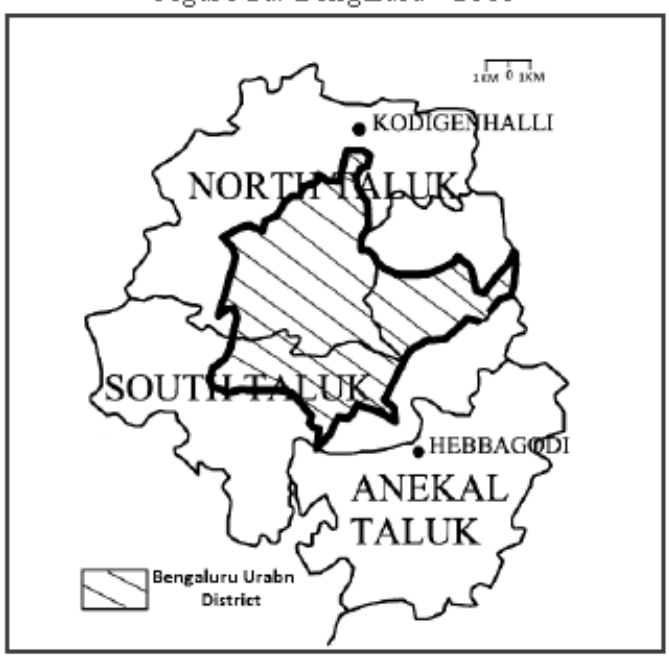

Figure 2.

Source: Census of India, 2001

\subsection{Bengaluru - Its Urban Primacy}

Like many typical cities in developing countries like India urban population has a general tendency of concentration in less fewer in number the metropolitan cities in spite of the other urban settlements being independent in all respect of urban living needs. Out of the total number of urban agglomerations situated in the state Karnataka, Bengaluru stands alone as far as maximum concentration of population. Following Zipf's method, the urban agglomerations lag behind from the expected urban population that they should carry due to the sole reason of overpopulation in Bengaluru, proving its urban primacy once again. Besides, there is another issue that may concern the Indian urban geographers. That is, if development is more sustaining than growth, then is growing Bengaluru retarding the growth proliferation of the other Urban Agglomerations in the same state and hence development? This becomes more visible when we gauge the zone of influence of the city based on population statistics and distances from it to the other growth foci of the state. Geographically situated in the southern part of Karnataka, Bengaluru poses influence as far as the northern to western part of the state at the 
farthest. This carries positive and negative impact on the growth centres other than Bengaluru. The primate city helps and encourages a pulling up of the lagging regions as far as economic and social development are concerned but that may not allow at least to a certain extent, the independent rise of the other urban centres leading to yet another debate related to balanced growth. For that matter, decentralization of the city may be a way out to ease out the urban congestion related to traffic, housing, basic amenities and slums. Analysis of increase in population has revealed that in the case of this city the major role has been played by the in-migration of people from the regions nearby and also from other states of the country rather as an effect of natural increase. Considering the two census years,2001 and 2011, it has been revealed that Bengaluru and Mysore Urban Agglomerations maintain their first and second position respectively in population parameter but Belgaum and Gulbarga have gained ranks in this respect whereas Mangalore has lost its third rank in urban primacy ordering. Bijapur, Bidar, Karwar, Shahabad, Sirsi, Arsikere, Bhatkal ,Athni, Kumta and Ankola being noticeable urban centres maintained their positions in urban population. Other urban settlements more or less gained and lost their ranks in this respect. Altogether, urban centres in Karnataka maintain a typical feature of urban primacy of Bengaluru, and rest following next in orders, all 'located' below the estimated population that could ensure a balanced distribution of population clinging around the aforesaid growth foci.

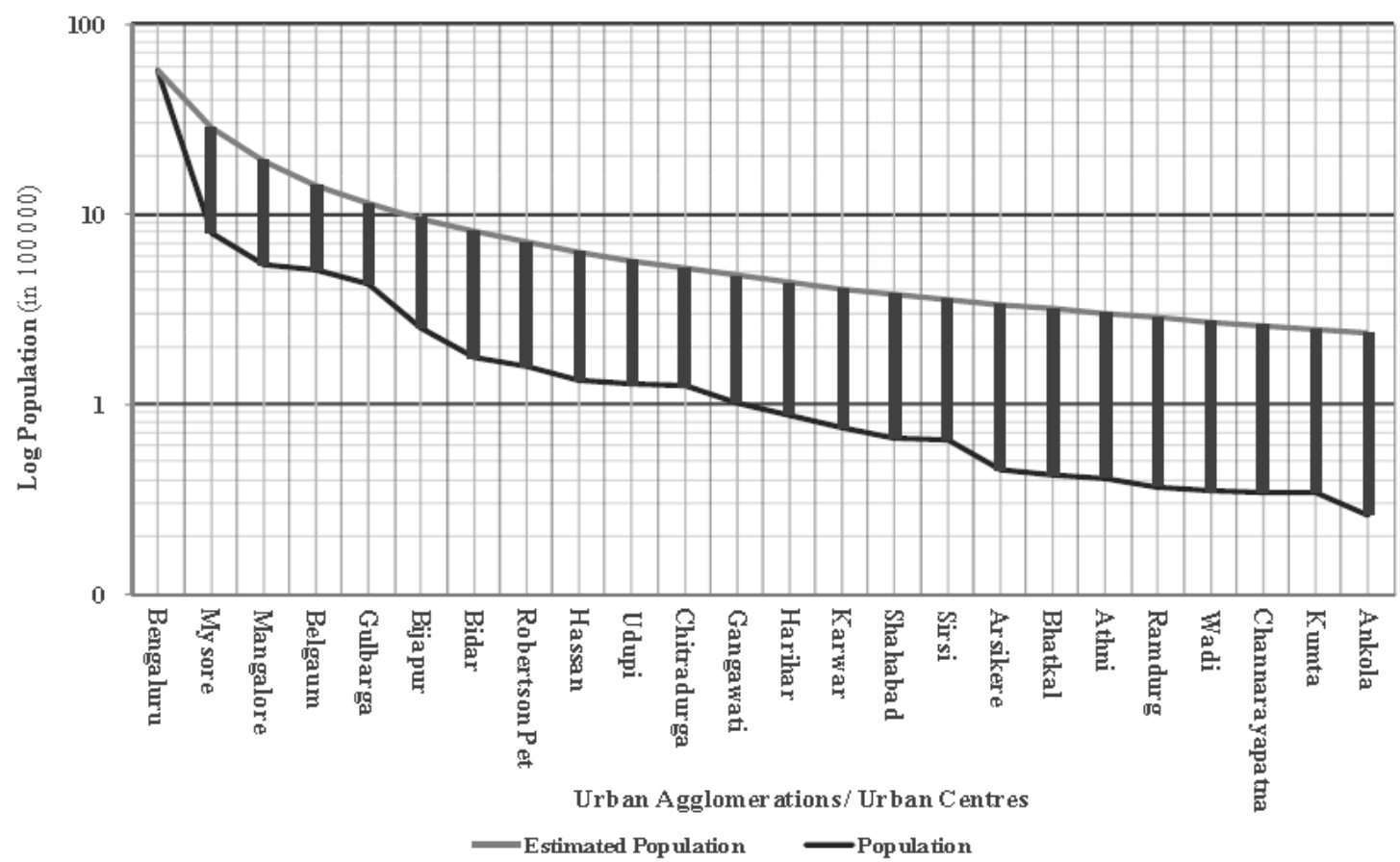

Figure 3a. Actual and estimated population of urban agglomerations in Karnataka - 2001 (adopted from Zipf's method)

Source: Census of India, 2001 


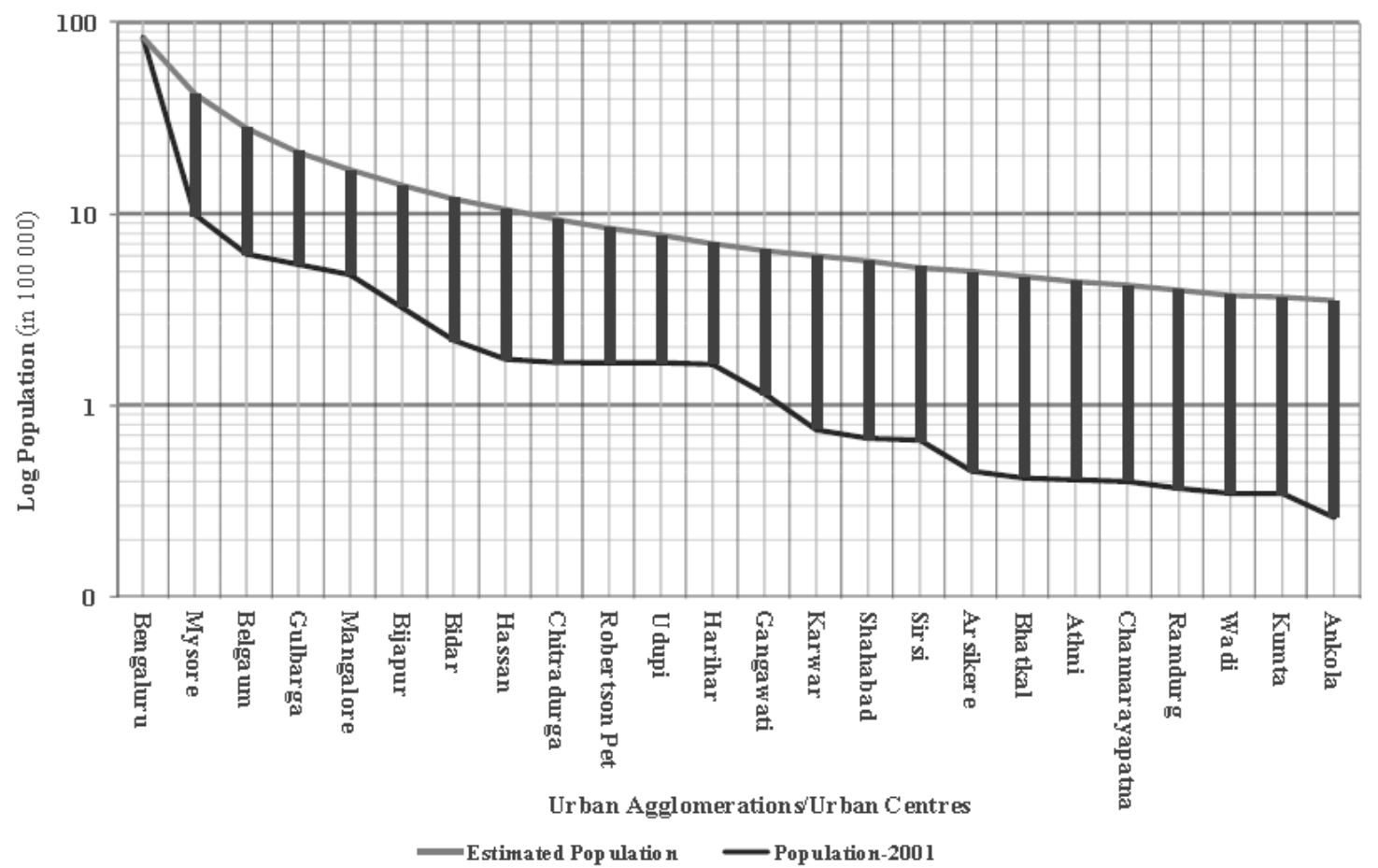

Figure 3b. Actual and estimated population of urban agglomerations in Karnataka - 2001 (adopted from Zipf's method)

Source: Census of India, (provisional) 2011

\subsection{Bengaluru - Its Zone of Influence}

Categorically speaking, the city once a kingdom of the Hindu and Muslim rulers perhaps today occupies the position of a growing centre of economy for India. However as mentioned earlier the city poses a wide deal of influence onto other small to medium populated urban centres which may cause a hindrance towards the natural growth of the later. Comparing the population of urban settlements for two consecutive decades such influences are revealed. Following the Gravity Model based on population between an important growth point to the remaining centres and the intervening distances between the two has been applied. Measuring zone of influence may be computed in such a way that makes more the distance( in kilometres) from the surrounding foci to the major centre joining each of them to one another, less would be the influence and vice versa. Considering Bengaluru as major growth centre, its influence on the rest of Karnataka based on the other urban centres, across the districts has been calculated. Of them, Mysore and Hassan though are noted urban agglomerations by themselves, due to their close proximity to the primate city (Bengaluru) share more influence of the later on them. Mysore has retained its rank in two consecutive decades though Hassan has lost its rank amongst high influence zone category with lesser impact of the Primate City in 2011 than in 2001. The rest of the centres mentioned in the High influence zone category, are indeed smaller towns and urban units, for which the gravity model states a higher degree of reliance on Bengaluru than themselves. Gangawati and Wadi are distant urban centres of Karnataka as compared to the location of Bengaluru having categorised into High Zone of Influence gaining ranks in this context from 2001 to 2011.Belgaum and Bhatkal have been categorised as Middle influence zone showing medium influence of Bengaluru on them in the year 2011 as compared to 2001 when they were under High zone of influence. They are heading towards a positive way of improvements as far as functionability as independent urban centres are concerned. Robertson Pet, Chitradurga ,Arsikere, Udupi, Gulbarga, Kumta,Bidar ,Ankola, Channarayapatna are comparatively smaller Urban centres which have gained rank as Middle Zone of Influence of Bengaluru that may be proved to be a good opportunity for them as far as 'pulling up' of the less important urban centres in the urban map of the region. Mangalore however, belonging to Low Influence zone in 2001 loses its rank in the same category in 2011 depicting more of its self content than relying upon the IT Capital of India. Sirsi along with other small to less developed urban units of Karnataka share their positions from High to Medium Influence zones that may be compatible to the urban planners as they plan for balanced regional development and decentralization of any single growth focal point(Table 1). The zone of influence is computed as: 


$$
\text { Zone of Influence }=\mathrm{Dij} / 1+\sqrt{P_{i} / P_{j}}
$$

Dij= Distance between Primate City \& the other Urban Centre / Growth Centre, Pi= Population of the Primate City; $\mathrm{Pj}=$ Population of the other Urban Centre / Growth Centre

Table 1. Bengaluru's zone of influence in Karnataka state (2001 \& 2011)

\begin{tabular}{|c|c|}
\hline 2001 & 2011 \\
\hline High Zone of Influence: $<1.5$ & High Zone of Influence: $<1.5$ \\
\hline Hassan & Wadi \\
\hline Athni & Gangawati \\
\hline Belgaum & Sirsi \\
\hline Mysore & Mysore \\
\hline Gangawati & Athni \\
\hline Wadi & Hassan \\
\hline Bhatkal & Robertson Pet \\
\hline Medium Zone of Influence: $1.5-3.8$ & Medium Zone of Influence: 1.5 - 4.5 \\
\hline Robertson Pet & Arsikere \\
\hline Karwar & Belgaum \\
\hline Arsikere & Chitradurga \\
\hline Chitradurga & Bidar \\
\hline Harihar & Gulbarga \\
\hline Sirsi & Udupi \\
\hline Shahabad & Harihar \\
\hline Bijapur & Bhatkal \\
\hline Low Zone of Influence:> 3.8 & Low Zone of Influence: $>4.5$ \\
\hline Udupi & Ankola \\
\hline Gulbarga & Kumta \\
\hline Ramdurg & Shahabad \\
\hline Mangalore & Karwar \\
\hline Kumta & Channarayapatna \\
\hline Bidar & Ramdurg \\
\hline Ankola & Bijapur \\
\hline Channarayapatna & Mangalore \\
\hline
\end{tabular}

Source: Provisional Population Totals Paper 1 of 2001 \& 2011; Karnataka, Census of India, Transport Plate, Karnataka (2006)

Holistically speaking Bengaluru Urban Agglomeration acts as a major growth centre for other parts of the state with enough opportunities for the jobseekers but at the same time pose hindrance for causing independent behaviour of the rest.

\section{Development Strategies}

The city development plan was prepared and approved for the city in 2006 as under the project Jawaharlal Nehru Urban Renewal Mission (JNNURM).It seeks to address the needs and challenges of the city in a systematic manner with following objectives:
1) Guided Growth of the City
2) Citizen's participation and awareness
3) Reform in governance leading to a well managed Society
4) Clear estimates of financial investments 


\section{5) Sustainability and further renewal}

The city is characterized by a radial system formed by mainly the transport axes, which converge towards its centre. The existing roads are Mysore road and old Madras road (South, South -West, North and North-East); Bellary road, Hosur road and Tumkur road. In addition, five other secondary roads complete the main framework like that of Magadi road in the west, Kanakapura road and Bannerghatta in the south and Varthur road and Whitefield road. The city today stretches in all directions and along these major roads corridors. The growth of urbanization along these areas seems to be determined by the industries while the inhabitants occupy the intermediary spaces. Urbanization in the south is driven by services sector (Electronic City and Bommasandra) and the resultant boom in the real estate market. There has been a slowdown in the west (Dasarahalli, Magadi road and Tumkur road) with the losing momentum of development of Peenya Industrial zone. Urbanization has increased in a substantial manner in the northeast and east, again due to upcoming service sector in the Whitefield and adjoining region and the current airport being within the city. Northern part of the city is now experiencing an exponential growth as the new airport is located in this part of the city named Devanahalli. This may trigger the expansion of the existing built up area to proceed further east. The projected land use in 2015 has been assessed in the Master Plan 2015 of Bangalore Development Authority and is indicated below in the Figure 4:

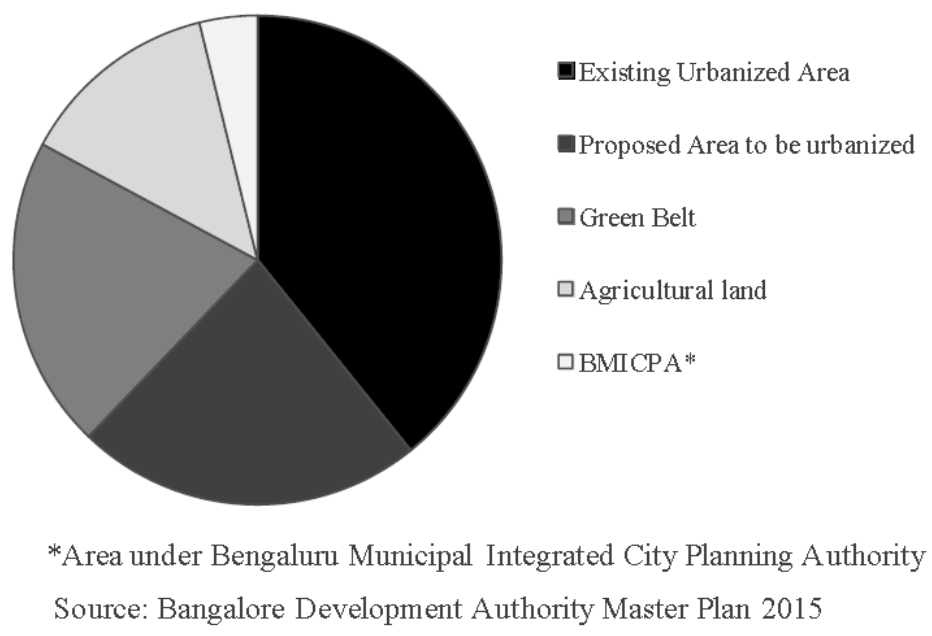

Figure 4. Land use components of Bangaluru

It should be noted here that the proposed area that has been planned to be urbanized includes the subcomponents of housing and industrial development. The rapid growth of the city over past few decades have resulted in growth beyond the city core into the rural district of Bengaluru besides being expanded into urban fringes adjacent to it. With this the Planning Authorities have taken up the task of establishing five satellite Townships along with renewal process of already existing urban areas of the city. While the growth of the city was basically with office space, it is trailed closely by residential, retail, hospitality and logistics/warehousing. The upcoming peripheral ring road, with a circumference of more than $110 \mathrm{~km}$, translates into a diameter of around $35 \mathrm{~km}$. Development has moved way past the outer ring road, to beyond the peripheral ring road in a period of less than five years and this is indicative of the growing borders of the city.

\section{Emergence of Satellite Towns and De-polarization of Bengaluru}

The concept of a Satellite Town in Urban Planning involves design of smaller towns governed under various municipalities more or less adjacent to a major growth centre .However they are markedly different from the concept of Suburbs, or fringe. Satellite Towns are expected to be self sufficient communities outside larger Metropolitan Conurbation but do experience interactive commutation. The following are the Satellite Towns planned so far to act as Spiller Cities of Bengaluru.

1) Bidadi Integrated Township

2) Ramanagara Township

3) Sathanur Township

4) Solur Township

5) Nandagudi Township

With a view to de-congest Bengaluru Metropolitan Area (Bruhat Bangalore Mahanagara Palike v \& Bangalore 
Development Authority Area) and direct further growth into the city region by way of comprehensive development of new human settlements in an integrated manner, BMRDA proposes to develop five New Integrated Townships with modern amenities and facilities at Bidadi, Ramanagaram, Sathanur, Solur and Nandagudi. The project is aimed at creating self-contained new integrated townships with work-live-play concept by integrating select economic activities in manufacturing/service/business categories. They are expected to offer the same or more comforts / facilities as available in Bangalore City minus the congestion, traffic bottlenecks in a serene and environmentally rejuvenating atmosphere. Series of road net work connecting these Townships with Bangalore City and Devanahalli International Airport is proposed by Bengaluru Metropolitan Regional Development Authority.

\section{Conclusion}

A complete journey from an overconcentration of population in a growing centre towards decentralization of the same can be only possible with proper planning, its execution and management. Typically a city like Bengaluru belonging to developing Nation perhaps face the major challenges in relation to haphazard growth with excessive population and growing needs of basic services like that of water supply, drainage, housing etc. Whatever functions do the cities perform it is essential to note that how far it plays role in the national and regional economy and there should be redistributional characteristics in it. The need for effective metropolitan governance is to address key problems and opportunities in an integrated and more meaningful way. Numerous challenges such as local and across the states migration, over spillage population and global threats of climate change and air pollution are posed in the future planning of the city.

\section{References}

Bangalore Development Authority. (2007). Bangalore Master Plan (2015): Volume I: Vision Document. Government of Karnataka, India.

Bangalore Metropolitan Regional Development Authority. (2010). A Report on Bidadi Integrated Township Project: Investor's Paradise. Government of Karnataka, India.

Human Development Report: The Real Wealth of Nations: Pathways to Human Development (2010), published by Oxford University Press, London.

Provisional Population Totals Paper1 of 2001, published by Census of India, Government of India.

Provisional Population Totals Paper1 of 2011, published by Census of India, Government of India. 